\title{
GENERATING 3D MODEL IN VIRTUAL REALITY AND ANALYZING ITS PERFORMANCE
}

\author{
Filip Popovski, Igor Nedelkovski and Svetlana Mijakovska \\ ${ }^{1}$ Faculty of Technical Sciences, St.Kliment Ohridski University - Bitola, Macedonia
}

\begin{abstract}
In this paper is presented an virtual environment of a real model. Here are given all analyzes for making and vizualization of virtual environment in Quest3D. All analyzes of performance of the system in real time is presented. We described advantages and disadvantages of interactions in virtual environment and made a critical analysis on a rendering speed and quality on different machines.
\end{abstract}

\section{KEYWORDS}

Virtual reality, Virtual environments, Scientific visualization, Computer design, Techniques of interaction.

\section{INTRODUCTION}

Virtual reality is use of computer technology to create effect of an interactive 3D world in which objects have a sense of spatial presence [1]. The primary difference between conventional 3D computer graphics and Virtual Reality is that in Virtual Reality we are working with things instead of pictures of things. Interaction is an essential characteristic of virtual environments. Much has been published about interaction techniques in VR, but searching for truly intuitive and natural interaction techniques is still going on. Interaction between users and virtual environments is very complex. Users must be able to navigate through $3 \mathrm{D}$ space, manipulate with virtual objects or control parameters of a simulation and interact with 3D GUI inside the virtual environment in a user-friendly way.

\section{SCIENTIFIC VISUALIZATION IN VIRTUAL REALITY}

For making 3D model, first step is collecting information about the real object and how it will be developed. Second step is collecting all necessary information, dimensions, colors, etc. Next step is creating textures for a given model. Each required texture is processed in Adobe Photoshop and then imported into software for virtual reality. For this research we used real model, a sports hall with dimensions $40 \mathrm{~m} \times 20 \mathrm{~m}$ with capacity for 500 peoples. 
International Journal of Computer Science \& Information Technology (IJCSIT) Vol 6, No 6, December 2014
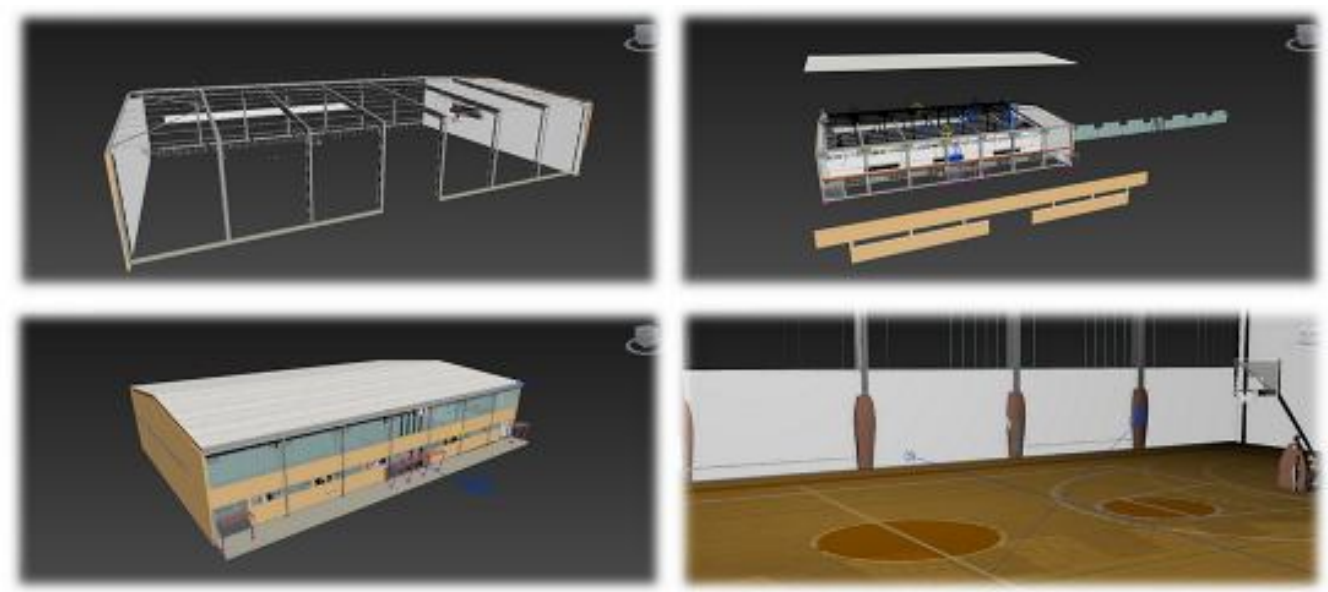

Figure 1. 3D model of a sport hall

After completing the process of modeling objects, space etc. in 3D Studio Max, we approach to their preparation for entry into Quest3D.

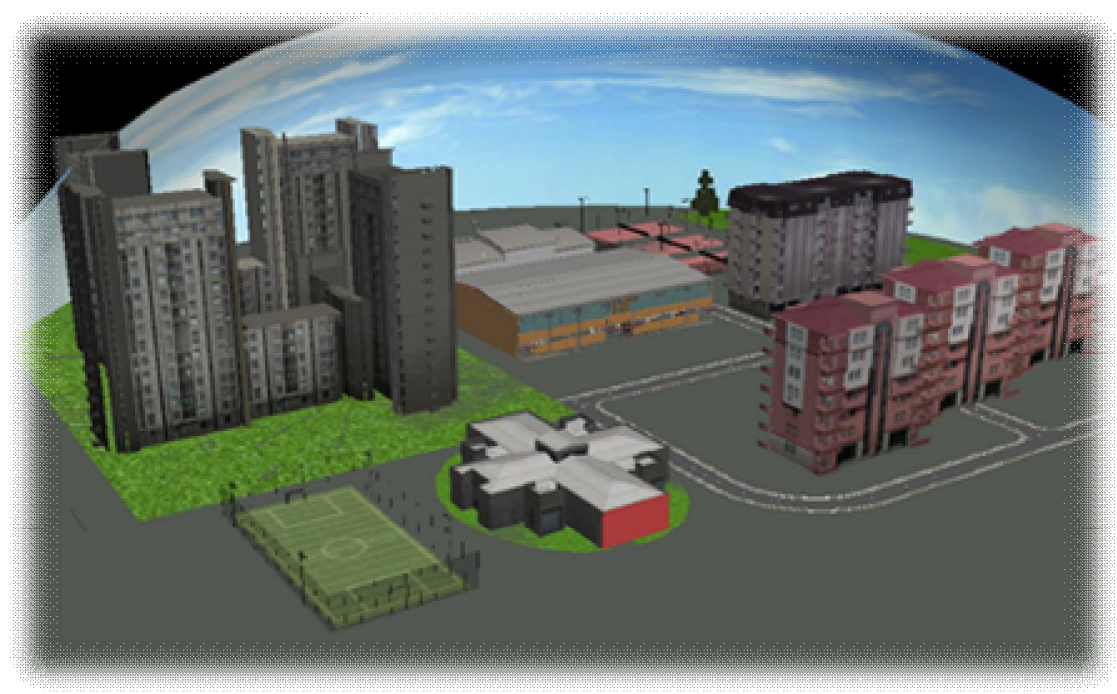

Figure 2. Virtual environment

On figure 3 is shown a comparison of the model in both softwares, 3D Studio Max and Quest3D. From it can be seen the difference of graphic quality on the same computer system. The quality of rendering in Quest3D is much better, with stronger colors and tones and much more realistic look. With that feeling, user have a better sense of comfort and immersion in virtual world. 


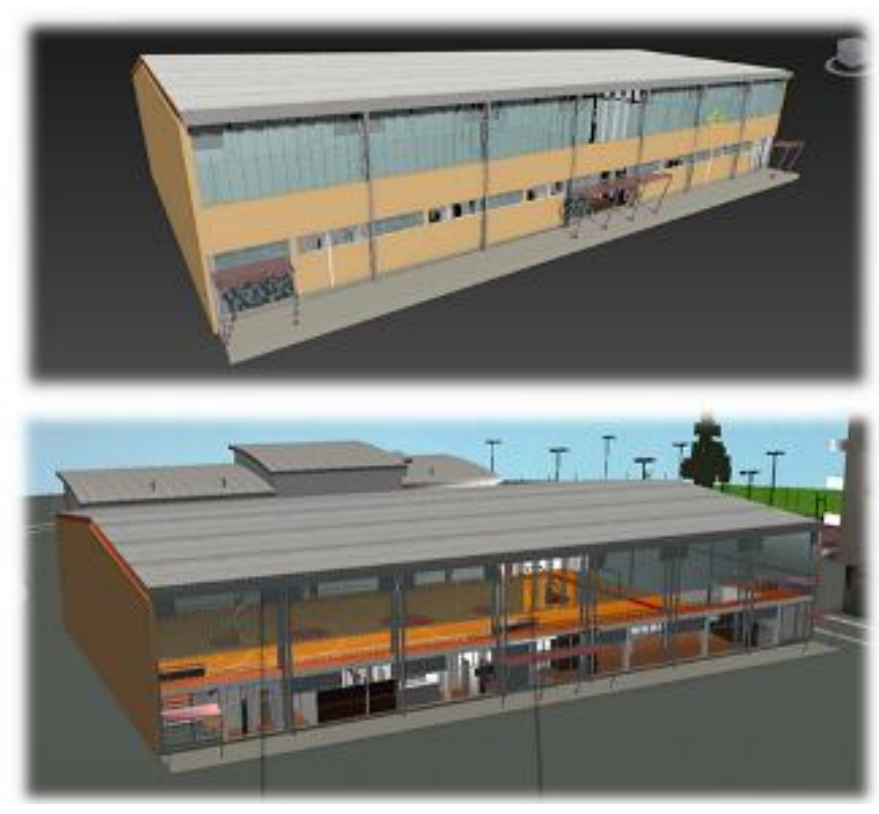

Figure 3. Comparation of a sport hall in 3D studio Max and Quest3D

Last comparation is performed on the objects in Quest3D, when displaying on various computer systems with different configurations. The purpose of this comparation is to show the dependence of aplication of computer components, especially graphics card. From images and configuration of computer systems can be seen that the difference in quality of rendering is very small. HP computer system rendered with slightly greater speed and quality versus computer system Toshiba. It it is due to better graphics card, faster processor and better screen resolution 1920x1200 pixels. However, rendering on computer system Toshiba has excellent quality and speed. On both computers the whole process was in real time.

Table 1.Virtual reality on different machines

\begin{tabular}{|c|c|c|}
\hline Category & $\begin{array}{c}\text { Specification - Toshiba Satellite } \\
\mathbf{A 6 6 0}\end{array}$ & $\begin{array}{c}\text { Specification - HP Z210 } \\
\text { Workstation }\end{array}$ \\
\hline CPU & Intel Core I5 2.27GHz & Intel Core I7 3.2GHz \\
\hline RAM Memory & $4 \mathrm{~GB}$ & $8 \mathrm{~GB}$ \\
\hline Graphic cards & $\begin{array}{c}\text { NVIDIA GeForce GT 330M, 1GB } \\
\text { DDR3 меморија }\end{array}$ & $\begin{array}{c}\text { AMD Firepro V5900 } \\
\text { 2GB GDDR5 меморија }\end{array}$ \\
\hline Resolution & 1366x768, 60Hz & $1920 \times 1200,60 \mathrm{~Hz}$ \\
\hline Hard Disk Space & $640 \mathrm{~GB}$ & $1 \mathrm{~TB}$ \\
\hline Operating System & Windows 7 64 Bit & Windows 7 64 Bit \\
\hline Quest 3D VR & Ver. 4.0 & Ver. 4.0 \\
\hline 3D Studio Max & 2013 & 2013 \\
\hline Photoshop & CS5 & CS5 \\
\hline
\end{tabular}




\section{TECHNIQUES OF INTERACTION IN VR}

Interaction between the objects in our model gives a sense of reality in virtual environment. In this case it relates to the interaction on shadows of the objects and their movement in real time. With every movement of objects in sport hall such as movement of the ball, shadows move together with ball under physical laws. Movements are in real time so that the user feels comfortable and real in a virtual environment.

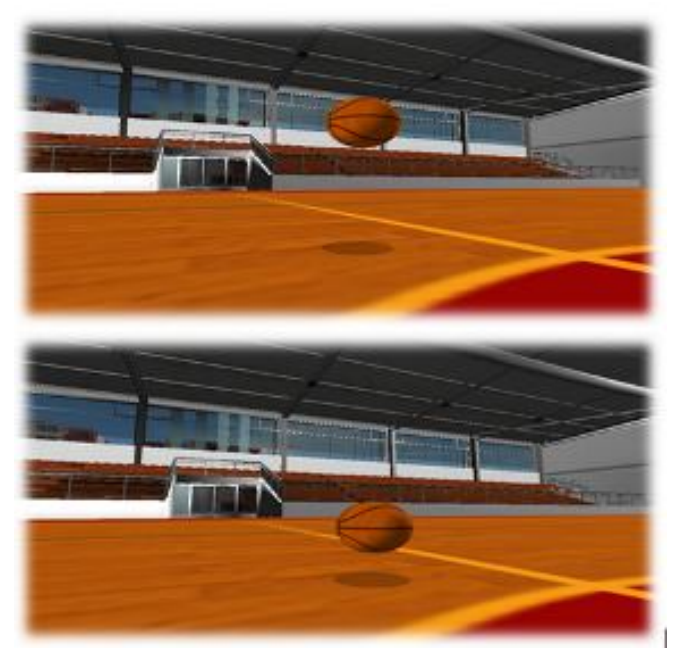

Figure 4. Real time simulation in virtual environment

Interactions with environment are an important characteristic of the virtual world that captures the user's view of virtual environment. It relates to the falling of sunlight on objects in virtual environment and their behavior or motion of their shadows, depending on the light source. Also, by reducing the intensity of light energy, decline the strength of a shadows. By moving light source from east to west, movements of a shadows of the objects in sports hall and its surroundings are opposite of the light source. External light enter through the windows in the hall, but also is strengthened with two spotlights which were added inside the hall .

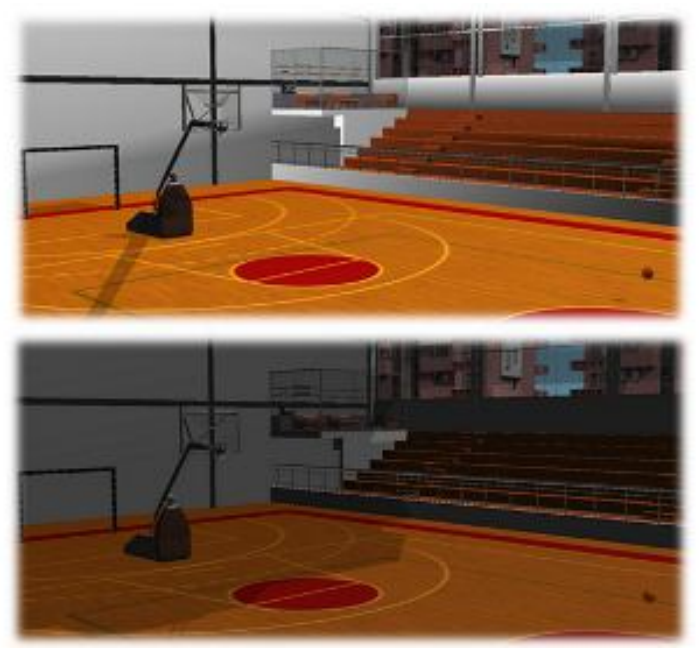

Figure 5. Real time interactions in virtual environment 


\section{Conclusions}

From the performed comparation, system performance is a very important feature when rendering proces is in real time. If application displays min. 10 frames per second, it is considered that it is in real time. Models presented in this paper displayed 25 frames per second. In extreme situations, it can speed up to 60 frames per second. This means that the user feels comfortable in our virtual environment. From the comparison on different computer systems is conducted that working in virtual environment in real-time, computer system should have min. 1GB RAM and a solid graphics card that supports DirectX 9. Graphical cards that we used in testing were good and with solid performance that had no problems. CPU speed should be at least $1 \mathrm{GHz}$ but our systems were stronger than that. Due to the high speed of rendering in some cases it have effect of motion blur.

Table 2. Analysis of the obtained results

\begin{tabular}{|c|c|c|}
\hline Category & Toshiba Satellite A660 & HP Z210 Workstation \\
\hline Rendering Quality & Good & Excelent \\
\hline Rendering Speed & Excelent & Excelent \\
\hline Real Time Rendering & Yes, with 25 frames/sec. & Yes, with 25 frames/sec. \\
\hline $\begin{array}{l}\text { Interactions between } \\
\text { objects in Real Time }\end{array}$ & Yes & Yes \\
\hline $\begin{array}{c}\text { Interactions with } \\
\text { environment }\end{array}$ & Yes & Yes \\
\hline $\begin{array}{r}\text { Minimum performace of } \\
\text { computer sistem for Real } \\
\text { Time rendering }\end{array}$ & $\begin{array}{c}\text { CPU Speed - 1GH } \\
\text { System memory - 1GB } \\
\text { Graphic card with DirectX } 9\end{array}$ & $\begin{array}{c}\text { CPU Speed - 1GH } \\
\text { System memory - 1GB } \\
\text { Graphic card with DirectX 9 }\end{array}$ \\
\hline
\end{tabular}

At our Faculty of Technical Sciences, we developed a model for interactive scientific visualization that is based on the following principles:

- User friendly interface;

- Using open soure libraries;

- Using computer monitor or LED TV;

- Unexpensive accessories needed for virtual navigation (HMD, virtual stick).

\section{REFERENCES}

[1] Bryson S., Virtual Environmenst in Scientific Visualisation, Proc. ACM VRST 94.

[2] Debevec P., Modelling and Rendering architecture from Photographs, University of California, 1996.

[3] Hill F., Computers Graphics Using Open GL, 2001.

[4] Moller T., Haines E., Hoffman N., Real Time Rendering, 2008.

[5] Parent R., Computer Animation - Algorithms and Techniques, Academic Press, San Diego, 2002.

[6] Pharr M., Humphreys G., Physically Based Rendering, Elsevier, San Francisco, 2004.

[7] Slusallek P., Vision An Architecture for Physically-Based Rendering, University of Erlangen, 1995.

[8] Smith B., 3ds Max 2008 Architectural Visualization, 3dats, 2007.

[9] Solomon D., Computer graphics and Geometric modelling, Springer, 1999.

[10] Turk S., Računarska grafika osnovi teorije i primena, Školska knjiga, Zagreb, 1980. 
International Journal of Computer Science \& Information Technology (IJCSIT) Vol 6, No 6, December 2014

[11] Bowman D. Hodges L., An Evaluation of Techniques for Grabbing and Manipulating Remote Objects in Immersive Virtual Environments, Proceedings of the ACM Symposium on Interactive 3D Graphics, New York, 2007

[12] Bowman D., Koller D., Hodges, L., Travel in Immersive Virtual Environments: An Evaluation of Viewpoint Motion Control Techniques, Proceedings of Virtual Reality Annual International Symposium, 1997.

[13] Hougaard M.H., Kolbe N., Larsen F.N.,Comparison of Tools for Developing Virtual Reality Application, Intermedia, Aalborg University, 2001.

[14] Kjeldskov, J.; Stage, J.; Interaction Styles in Development Tools for Virtual Reality Applications, Springer-Verlag, Berlin, 2003.

[15] Boudoin, P.; Otmane, S.; Mallem, M.; Design of a 3D Navigation Technique Supporting VR Interaction, CISA, Annaba, Algeria, 2008.

[16] Vogelmeier, L.; Neujahr, H.; Sandl, P.; Interaction Methods for Virtual Reality Applications, Virtual Media for Military Applications, West Point, NY, 2006.

\section{Authors}

Mr.Filip Popovski is an Assistant Professor in Graphic Engineering, Faculty of Technical Sciences, Bitola, Macedonia. He is currently working on his doctoral thesis, and he is interested in computer graphics, visualization.

Mr.Igor Nedelkovski is a Doctor of Technical Sciences, Faculty of Technical Sciences, Bitola, Macedonia. He is interested in Computer Aided Engineering.

Ms.Svetlana Mijakovska is an Assistant Professor in Graphic Engineering, Faculty of Technical Sciences, Bitola, Macedonia. She is currently working on her doctoral thesis, and she is interested in computer graphics, $3 \mathrm{~d}$ modelling, graphic design, web design and computer vision.
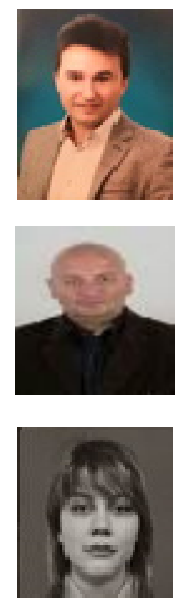